\title{
The EULAR points to consider for health professionals undertaking musculoskeletal ultrasound for rheumatic and musculoskeletal diseases
}

Musculoskeletal ultrasound has evolved into an important clinical decision-making tool by assisting in the diagnosis of inflammatory arthritis, monitoring disease activity and therapeutic response, and guiding interventions. ${ }^{1-7}$ The role of the nonmedical health professional has advanced, with many undertaking training and using musculoskeletal ultrasound to improve patient care and in doing so, increasing their scope of practice. Health professionals with clinical expertise and experience using ultrasound are also providing training for colleagues and medical clinicians.

As previously described among rheumatologists, ${ }^{8} 9$ the use of musculoskeletal ultrasound and training undertaken varies significantly between different professional groups and across Europe. Guidelines to support training for rheumatologists have been formulated ${ }^{10}$ but currently there are no recommendations to support the education and training needs of non-medical health professionals using musculoskeletal ultrasound.

A European League Against Rheumatism (EULAR) task force was established to reach a consensus on the role of, and education and training needs of health professionals undertaking musculoskeletal ultrasound for the management of people with rheumatic and musculoskeletal diseases (RMDs).

The group comprising of 18 clinical and academic experts representing 10 European countries included rheumatologists, nurses, physiotherapists, an epidemiologist, methodologist, radiologist, radiographer and podiatrist, and people with RMDs, who defined the aims and formulated 14 research questions to guide a comprehensive systematic literature search (SLR). The results of the SLR were discussed and supported the formulation of points to consider and a research agenda.

Table 1 Points to consider for health professionals undertaking musculoskeletal ultrasound for rheumatic and musculoskeletal diseases

Overarching principle

All health professionals may use musculoskeletal ultrasound, following appropriate training, within their scope of clinical practice and professional background

Level of agreement

Points to consider

evidence statement mean $(95 \% \mathrm{Cl})$

Role and scope

1. Health professionals may use ultrasound to detect musculoskeletal abnormalities and contribute to clinical decision-making.

2. Health professionals may use musculoskeletal ultrasound as a tool for research including health professional-led studies.

$\begin{array}{lll}3-4 & \text { D } & 9.2(8.8 \text { to } 9.7) \\ 3-4 & \text { D } & 9.3(8.7 \text { to } 9.9) \\ 4 & \text { D } & 9.7(9.5 \text { to } 10.0) \\ 3-4 & \text { D } & 9.6(9.2 \text { to } 10.0)\end{array}$

Training and competency

3. Health professionals must be appropriately trained and assessed for competency in musculoskeletal ultrasound before applying it in clinical practice.

4. The minimal competency requirements for performing musculoskeletal ultrasound must be the same for all ultrasound practitioners. Advanced training content may be adapted according to the needs of the health professionals.

5. Health professionals appropriately trained may teach musculoskeletal ultrasound according to a standardised and formalised training programme.

$4 \quad$ D

D

$9.5(9.1$ to 9.9$)$

Application and feasibility

6. The use of musculoskeletal ultrasound by health professionals must be based on levels of competency and the individual's role within their institution/department, as directed by local and national regulations.

3-4

D

$9.6(9.4$ to 9.9$)$

Additional value

7. By using musculoskeletal ultrasound, health professionals may improve the clinical management of people with rheumatic and musculoskeletal diseases. 


\section{Box 1 Future research agenda}

1. To determine the musculoskeletal ultrasound training needs of European League Against Rheumatism (EULAR) health professionals and how they intend to use ultrasound.

2. To develop a structured EULAR advanced musculoskeletal ultrasound training programme specific to the needs of health professionals.

3. To determine the provision of mentorship that health professionals will require to support their training needs in musculoskeletal ultrasound.

4. To understand the impact of health professionals performing musculoskeletal ultrasound on the care of people with rheumatic and musculoskeletal diseases.

5. To determine the cost effectiveness of models of care in which health professionals are using musculoskeletal ultrasound.

6. To determine and standardise the minimum requirements for reporting musculoskeletal ultrasound examinations performed by health professionals.

7. To evaluate the influence of the EULAR points to consider on the use of musculoskeletal ultrasound by health professionals.

Seven points to consider were formulated (table 1) encompassing the role and scope of health professionals using musculoskeletal ultrasound, including the application, feasibility and added value in daily practice, and the training and competencies required. The strength of the points to consider was rated D based on the category of evidence (3-4). A high level of agreement (range 9.0-9.7) was reached by the task force members. The task force agreed on seven topics for the research agenda (box 1).

These are the first points to consider produced by a EULAR task force for health professionals using musculoskeletal ultrasound. The task force acknowledged that there is weak evidence supporting the points to consider, which were developed using a combination of research-based evidence and expert consensus. The use of musculoskeletal ultrasound by health professionals in both clinical practice and research is increasing in popularity, hence these points to consider are timely. It is envisaged that they will need to be revisited as new evidence becomes available.

The seven points to consider are intended to support the education and training needs for health professionals using musculoskeletal ultrasound across Europe. It is important to note that these points to consider should be used in conjunction with local and national regulations. There was consensus that the role and scope of ultrasound practice for non-medical sonographers does not differ significantly from that applying to rheumatologists, and therefore the training and competency levels should be the same for rheumatologists and health professionals using musculoskeletal ultrasound in clinical practice and for research.

A full description of the SLR and points to consider development are available at http://www.eular.org.

Heidi J Siddle, ${ }^{1,2}$ Peter Mandl, ${ }^{3}$ Daniel Aletaha, ${ }^{3}$ Thea P Vliet Vlieland, ${ }^{4}$ Marina Backhaus, ${ }^{5}$ Patricia Cornell, ${ }^{6}$ Maria-Antonietta D'Agostino, ${ }^{1,7}$ Karen Ellegaard, ${ }^{8}$ Annamaria lagnocco, ${ }^{9}$ Bente Jakobsen, ${ }^{10}$ Tiina Jasinski, ${ }^{11}$ Nina H Kildal, ${ }^{12}$ Michaela Lehner, ${ }^{3}$ Ingrid Möller, ${ }^{13}$ Gabriela M Supp, ${ }^{3}$ Philip 0'Connor, ${ }^{2,14}$ Anthony C Redmond, ${ }^{1,2}$ Esperanza Naredo, ${ }^{15}$ Richard J Wakefield ${ }^{1,2}$
${ }^{1}$ Leeds Institute of Rheumatic and Musculoskeletal Medicine, University of Leeds, Leeds, UK

${ }^{2}$ NIHR Leeds Musculoskeletal Biomedical Research Centre, Leeds, UK

${ }^{3}$ Division of Rheumatology, Medical University of Vienna, Vienna, Austria

${ }^{4}$ Department of Orthopaedics, Rehabilitation and Physical Therapy, Leiden University Medical Centre, Leiden, The Netherlands

${ }^{5}$ Department of Internal Medicine, Rheumatology and Clinical Immunology, Academic Hospital of the Charité Berlin, Berlin, Germany

${ }^{6}$ Department of Rheumatology, Poole Hospital NHS Foundation Trust, Poole, UK ${ }^{7}$ Laboratoire d'Excellence INFLAMEX, Versailles-Saint-Quentin University, SaintQuentin en Yvelines, France

${ }^{8}$ The Parker Institute, Copenhagen University Hospital Bispebjerg-Frederiksberg, Copenhagen, Denmark

${ }^{9}$ Rheumatology Unit—Dipartimento di Medicina Interna e Specialità Mediche, Sapienza Università di Roma, Rome, Italy

${ }^{10}$ National Advisory Unit on Pregnancy and Rheumatic Diseases, St. Olavs Hospital, Trondheim, Norway

${ }^{11}$ Patient Research Partner, Estonian Rheumatism Association, Tallinn, Estonia

${ }^{12}$ Faculty of Health and Social Science, Norwegian University of Science and

Technology, Trondheim, Norway

${ }^{13}$ Instituto Poal de Reumatologia, Barcelona, Spain

${ }^{14}$ Department of Radiology, Leeds Teaching Hospitals NHS Trust, Leeds, UK

${ }^{15}$ Department of Rheumatology, Hospital GU Gregorio Marañón, Madrid, Spain

Correspondence to Dr Heidi J Siddle, Leeds Institute of Rheumatic and Musculoskeletal Medicine, University of Leeds, Chapel Allerton Hospital, Chapeltown Road, Leeds LS7 4SA, UK; h.siddle@leeds.ac.uk

Acknowledgements The authors thank Sue Oliver, OBE for her leadership in the conception of this project. The authors also thank Deirdre Andre, Scholarly Communications and Research Skills Advisor, Leeds University Library for her support in conducting the systematic literature review.

Contributors HJS was the research fellow for the project, undertaking the SLR RJW was the project convener; PM, DA and TPVV provided epidemiology direction for the SLR and the project. HJS and RJW were responsible for drafting the manuscript. All those listed as authors were responsible for developing the points to consider and reading, commenting on, and approving the final manuscript. All contributors were independent from the study funders in conducting the research.

Funding This project was supported by the European League Against Rheumatism (EULAR). The research is supported by the National Institute for Health Research (NIHR) Leeds Musculoskeletal Biomedical Research Centre, UK. The views expressed are those of the authors and not necessarily those of the NHS, the NIHR or the Department of Health.

Competing interests None declared.

Provenance and peer review Not commissioned; externally peer reviewed.

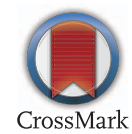

To cite Siddle HJ, Mandl P, Aletaha D, et al. Ann Rheum Dis 2018;77:311-313.

Received 28 October 2016

Accepted 22 November 2016

Publishe Online First 9 December 2016

Ann Rheum Dis 2018:77:311-313. doi:10.1136/annrheumdis-2016-210741

\section{REFERENCES}

1 Wakefield RJ, Gibbon WW, Conaghan PG, et al. The value of sonography in the detection of bone erosions in patients with rheumatoid arthritis: a comparison with conventional radiography. Arthritis Rheum 2000;43:2762-70.

2 Karim Z, Wakefield RJ, Conaghan PG, et al. The impact of ultrasonography on diagnosis and management of patients with musculoskeletal conditions. Arthritis Rheum 2001:44:2932-3.

3 Terslev L, Torp-Pedersen S, Savnik A, et al. Doppler ultrasound and magnetic resonance imaging of synovial inflammation of the hand in rheumatoid arthritis: a comparative study. Arthritis Rheum 2003;48:2434-41.

4 d'Agostino MA, Ayral X, Baron G, et al. Impact of ultrasound imaging on local corticosteroid injections of symptomatic ankle, hind-, and mid-foot in chronic inflammatory diseases. Arthritis Rheum 2005:53:284-92.

5 Brown AK, Quinn MA, Karim Z, et al. Presence of significant synovitis in rheumatoid arthritis patients with disease-modifying antirheumatic drug-induced clinical remission: evidence from an imaging study May explain structural progression. Arthritis Rheum 2006;54:3761-73. 
6 Koski JM, Saarakkala S, Helle M, et al. Assessing the intra- and inter-reader reliability of dynamic ultrasound images in power Doppler ultrasonography. Ann Rheum Dis 2006;65:1658-60.

7 Naredo E, Collado P, Cruz A, et al. Longitudinal power Doppler ultrasonographic assessment of joint inflammatory activity in early rheumatoid arthritis: predictive value in disease activity and radiologic progression. Arthritis Rheum 2007:57:116-24.

8 Naredo E, D'Agostino MA, Conaghan PG, et al. Current state of musculoskeletal ultrasound training and implementation in Europe: results of a survey of experts and scientific societies. Rheumatology (Oxford) 2010;49:2438-43.

9 Mandl P, Naredo E, Conaghan PG, et al. Practice of ultrasound-guided arthrocentesis and joint injection, including training and implementation, in Europe: results of a survey of experts and scientific societies. Rheumatology (Oxford) 2012;51:184-90.

10 Terslev L, Hammer HB, Torp-Pedersen S, et al. EFSUMB minimum training requirements for rheumatologists performing musculoskeletal ultrasound. Ultraschall Med 2013;34:475-7. 